\title{
G20 Okayama Health Ministers' Meeting: Conclusions and commitments
}

\section{Hideaki Nishizawa $^{1^{*}}$, Yoshito Nishimura ${ }^{2 *}$, Hiroshi Matsumura ${ }^{1}$, Hisayo Horiuchi ${ }^{1}$, Toshitaka Higashira $^{1}$, Yosuke Kita ${ }^{1}$, Yasuyuki Sahara ${ }^{1}$, Yasuhiro Suzuki $^{1}$}

\footnotetext{
${ }^{1}$ Ministry of Health, Labour and Welfare, Tokyo, Japan

2 Department of General Medicine, Okayama University Graduate School of Medicine, Dentistry and Pharmaceutical Sciences, Okayama, Japan

* Joint first authorship.
}

The third G20 Health Ministers' Meeting in Okayama in October 2019 highlighted "the Achievement of Universal Health Coverage," "Response to Population Ageing," and "Management of Health Risk and Health Security including Antimicrobial Resistance" as the main pillars.

\section{UNIVERSAL HEALTH COVERAGE}

There are several key messages in the G20 Okayama Health Ministers' Declaration [4]. As the meeting was the first important one on global health after the United Nations High-Level Meeting on UHC in September, the Ministers reaffirmed their commitment to achieve UHC by 2030 and agreed on the direction of specific policy measures toward achieving this goal. Ahead of the G20 Summit in June, McBride and colleagues pointed out that G20 health agendas lacked greater commitment to equity [5]. The Ministers expressed their firm determination to advance the health-related sustainable development goals (SDGs) and UHC in the Declaration. Additionally, the importance of building human resources to develop health policies was stressed in the deliverables. Naturally, frontline officers have significant requirements to practically implement high-level messages, and they were verbalized to expedite specific actions. One of the important aspects of the Ministers' Declaration was the collaboration of the health and finance sectors. As affirmed in the first G20 Joint Session of Ministers of Finance and Health and as pointed out in the World Bank's report [6], their collaboration is essential to secure the sustainability of health financing. As Dieleman and colleagues mentioned, the G20 has a substantial role in developing assistance for health [7]. While the G20 and international organizations should help developing countries in need, their domestic financing also needs to be strengthened. The G20 Shared Understanding on the Importance of UHC Financing in Developing 
The G20 Okayama Health Ministers' Meeting was a milestone in global health, where the Ministers agreed on the direction of policy measures to accelerate progress in global health. Concrete actions by G20 members are now required.
Countries [8], to which finance and health ministers of G20 affirmed their commitments, identifies several key considerations to strengthen health system towards UHC.

\section{POPULATION AGEING}

Population ageing is a new challenge facing the G20 HMM. Although Japan has always been at the forefront of the issue, it has now become a global agenda. The Declaration highlighted prioritization of active and healthy ageing and the importance of preventive measures to avoid ill-health over one's life course. The Ministers also stressed the importance of multi-sectoral policy responses to dementia, such as promoting risk reduction and offering inclusive environments, by developing national action plans that have not yet been implemented by all the G20 members. The G20 members are diverse in terms of the pace and stage of population ageing, and the Ministers agreed to continue to share their experiences and play a role in building better policy responses together.

\section{HEALTH EMERGENCIES AND AMR}

Regarding the management of health emergencies, the Ministers agreed that there was still room for enhancing preparedness and responses to global health threats, as indicated by the current Ebola Virus Disease (EVD) outbreak in the Democratic Republic of Congo, despite the substantial improvement in the global health security architecture after the 2014 EVD outbreaks in West Africa. They also agreed to encourage contributions to secure sustainable global financing mechanisms such as the World Health Organization Contingency Fund for Emergencies. Given that it is mostly funded by Germany, Japan, and the United Kingdom, diversifying the donor base is an urgent issue for this essential health emergency countermeasure [9]. The Ministers also agreed to strengthen their efforts to tackle AMR by enhancing stewardship and encouraging investment in the research and development of new antimicrobials.

\section{CONCLUSIONS}

The G20 Okayama HMM was a milestone in global health; the Ministers agreed on the direction of policy measures to achieve UHC, presented responses to population ageing as a major global health

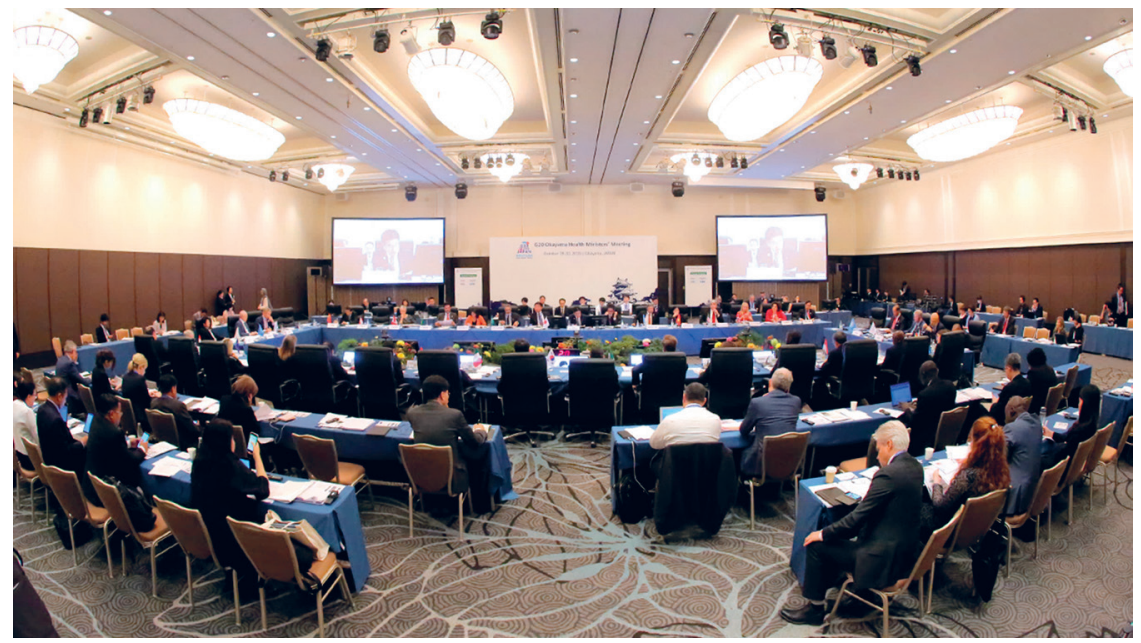

Photo: Health Ministers engaging in discussion to make progress in global health (from the website of the Ministry of Health, Labour and Welfare of Japan, used with permission. https://www.mhlw.go.jp/ seisakunitsuite/bunya/hokabunya/kokusai/g20/health/jp/photos_g20okayama.html). issue, and strengthened efforts to improve global health risk management and tackle AMR. As indicated in the article published after the G20 Osaka Summit on July 6 [10], we believe that concrete actions by G20 members based on the Declaration are now needed to make substantial progress in global health. In 2020, the Saudi G20 Presidency proposed "Enabling Person-Centered Health Systems" with a focus on value-based health care and digital health solutions as the main pillar of the health agenda [11]. We hope that the next Presidency will accelerate progress in global health, building on the legacy of the previous G20 HMM. 


Acknowledgments: We thank our colleagues in the Ministry of Finance and the Ministry of Foreign Affairs who
helped us organize the G2O Health Ministers' Meeting.
Funding: None.
Authorship contributions: HN and YN are the co-lead authors and wrote the manuscript. HM and HH reviewed
and edited the "Universal Health Coverage" and the "Population Ageing" sections. TH revised the "Health emergencies
and AMR" section, YK, Y Sahara, and Y Suzuki reviewed the existing references and edited the entire draft manu-
script.
Competing interests: The authors have completed the ICMJE Unified Competing Interest form (available on re-
quest from the corresponding author) and declare no competing interests.

1 De Vogli R, Gimeno D. The G20 and the three global crises: what prospects for global health? J Epidemiol Community Health. 2010;64:99-100. Medline:20056960 doi:10.1136/jech.2009.094789

2 Pakes BN, Philpott J, Redwood-Campbell L, Rouleau K. Toronto's G20 one year later: missed opportunity for a Canadian contribution to global health. Can Fam Physician. 2011;57:650-3. Medline:21673205

3 Ministry of Foreign Affairs of Japan. G20 Osaka Leaders' Declaration. Available: https://www.g20.org/en/documents/final_g20_osaka_leaders_declaration.html. Accessed: 24 November 2019.

4 Ministry of Health, Labour, and Welfare of Japan. Okayama Declaration of the G20 Health Ministers, October 19-20, 2019. Available: https://g20-meeting2019.mhlw.go.jp/health/img/G20Okayama_HM_EN.pdf. Accessed: 24 November 2019.

5 McBride B, Hawkes S, Buse K. Soft power and global health: the sustainable development goals (SDGs) era health agendas of the G7, G20 and BRICS. BMC Public Health. 2019;19:815. Medline:31234831 doi:10.1186/s12889-019-7114-5

6 World Bank. High-performance health financing for universal health coverage (vol. 2): driving sustainable, inclusive growth in the 21st century. Available: http://documents.worldbank.org/curated/en/641451561043585615/pdf/Driving-Sustainable-Inclusive-Growth-in-the-21st-Century.pdf. Accessed: 24 November 2019.

7 Dieleman JL, Cowling K, Agyepong IA, Alkenbrack S, Bollyky TJ, Bump JB, et al. The G20 and development assistance for health: historical trends and crucial questions to inform a new era. Lancet. 2019;394:173-83. Medline:31257126 doi:10.1016/S0140-6736(19)31333-9

8 Ministry of Finance of Japan. G20 Shared Understanding on the Importance of UHC Financing in Developing Countries - Towards sustainable and inclusive growth - June 6, 2019. Available: https://www.mof.go.jp/english/international_policy/convention/g20/annex8_1.pdf. Accessed: 17 February 2020.

9 World Health Organization. Contingency fund for emergencies (CFE). Available: https://www.who.int/emergencies/funding/contingency-fund/en/. Accessed: 26 November 2019.

10 The Lancet. G20 Osaka: when will global health commitments be realised? Lancet. 2019;394:1. Medline:31282344 doi:10.1016/S0140-6736(19)31520-X

11 G20 Saudi Arabia. 2020. Realizing opportunities of the 21st Century for All. Available: https://g20.org/en/g20/Documents/Presidency\%20Agenda.pdf. Accessed: 11 February 2020.

\section{Correspondence to:}

Yoshito Nishimura

Department of General Medicine Okayama University Graduate School of Medicine, Dentistry and Pharmaceutical Sciences

2-5-1 Shikata-cho

Kita-Ku

Okayama

Japan

nishimura-yoshito@okayama-u.ac.jp 